\title{
INVESTIGANDO PERMANÊNCIAS AFRICANAS
}

\author{
ARIADNE GUIMARÃES DIAS*
}

\section{RESUMO}

$\mathrm{O}$ presente artigo tem por objetivo apresentar as linhas-chave da dissertação de mestrado que investiga a presença africana no jornal “A Voz da Raça”, publicado entre os anos de 1933 a 1937, na cidade de São Paulo. Para isso são definidos três momentos/ situação-problema: 1. Investigação do personagem, objeto da pesquisa, o negro no início do século passado (XX), em São Paulo (SP); 2. As ideologias nas quais ele se encontrava imerso, em especial o discurso criado, defendido e propagado pelo Racismo Científico e 3. A resposta da população negra no fenômeno que ficou conhecido como a Imprensa Negra, em especial, no jornal da Frente Negra Brasileira (FNB). Estruturado como um trabalho historiográfico, interdisciplinar com fonte primária, de base qualitativa, exploratória-descritiva, a dissertação desenvolveu métodos de pesquisa que permitissem a identificação da permanência da matriz africana entre os "filhos" da diáspora no jornal dos frentenegrinos, propiciando a recuperação de um momento crucial da história dos negros no Brasil, bem como a divulgação dos nomes dos homens que ajudaram a promover essa diferença.

Palavras-chave: A Voz da Raça, Frente Negra Brasileira (FNB), Imprensa Negra, Educação e Racismo.

* Dissertação de Mestrado em Educação - "A Voz da Raça, os Ecos da Educação: Percepções sobre as Permanências da Herança Cultural Africana no Brasil”, defendida por esta autora, na Escola de Comunicação, Educação e Humanidades do Programa de Pós-graduação em Educação (UMESP). Orientador - Prof. Dr. Marcelo Furlin. 


\begin{abstract}
The present article aims to present the key lines of the master's thesis that investigates the African presence in the newspaper "The Voice of the Race", published between the years of 1933 and 1937. For this, three moments / problem situation are defined: 1. Investigation of the character, object of the research, the black at the beginning of the last century (XX), in São Paulo (SP); 2. The ideologies in which he was immersed, especially the discourse created, defended and propagated by Scientific Racism and 3. The response of the black population in the phenomenon that became known as the Black Press, especially in the newspaper of the Frente Negra Brasileira (FNB). Structured as a historiographic, interdisciplinary work with a primary source, with a qualitative, exploratory-descriptive basis, the dissertation developed research methods that allowed the identification of the permanence of the African matrix among the "children" of the diaspora in the journal of the Frentenegrinos, providing the recovery of a moment the history of blacks in Brazil, as well as the dissemination of the names of the men who helped to promote this difference.
\end{abstract}

Keywords: A Voz da Raça, Frente Negra Brasileira (FNB), Black Press, Education e Racism.

O resgate da permanência e pontos de identificação entre africanos e seus descentes na diáspora. Esse é o leitmotiv da dissertação de mestrado "A Voz da Raça, os Ecos da Educação: Percepções sobre as Permanências da Herança Cultural Africana no Brasil". O desejo de "garimpar" nas páginas do jornal da Frente Negra Brasileira (FNB) os ecos do continente-origem, as raízes africanas existentes nos textos do mais importante movimento negro do país. Para isso foi traçado um caminho de investigação que incluiu a leitura das pesquisas desenvolvidas por historiadores, sociólogos e antropólogos sobre o movimento. Os estudos envolveram também teses, dissertações, monografias e artigos sobre o tema, bem como a análise dos trabalhos que contextualizam o momento histórico conhecido como Imprensa Negra Paulista. 
Este trabalho historiográfico, interdisciplinar, com pesquisa em fonte primária e outras publicações do período investigado procurou observar as relações de significado preservadas e recriadas no pós-escravidão, a partir de um roteiro composto de três etapas: a personagem, a cena e a voz. Em seu primeiro momento optou-se pela identificação do negro, elemento-chave da pesquisa, sua realidade e anseios no início do século XX. Posteriormente os esforços foram concentrados na recuperação das ideologias que formataram o discurso racista no mundo e as especificidades brasileiras. $\mathrm{Na}$ terceira e derradeira fase foram analisados a expressão, o discurso da comunidade, as questões que mobilizaram os negros brasileiros da ocasião e os "acessos", conscientes ou não, à matriz africana.

O entendimento da importância desse material para a educação dos brasileiros alinha-se com a proposta da Lei 10.639/03, que torna obrigatório o ensino da história e da cultura afro-brasileira e africana em todas as escolas, públicas e particulares, do ensino fundamental até o ensino médio no Brasil. E direciona a pesquisa a uma leitura pedagógica dos materiais encontrados. O texto, portanto, é construído a partir da reflexão mandatória de que a análise do passado, a reeducação das relações étnicas e o aprendizado da história e culturas dos povos que vieram da África e seus descentes são fundamentais para a formação do homem, que, à definição do filósofo Immanuel Kant ${ }^{1}$, deve ser entendido como um ser "infante, educando e discípulo" ("Sobre a Pedagogia”, 5. ed. Piracicba: Unimep, 2006).

Nesta viagem os primeiros esforços se concentraram no resgaste da personagem, o negro brasileiro, seus desafios e vivências no início do século XX, em São Paulo, na compreensão do cenário brasileiro pós-abolição e suas implicações econômicas e sociais. O fichamento das obras dos sociólogos Florestan Fernandes e Roger Bastide e os depoimentos de contemporâneos auxiliaram a recompor o cenário de desordem

Filósofo alemão (1724-1804). Considerado o pai do pensamento moderno, Kant ministrou regularmente o curso de Pedagogia na Universidade de Königsberg, na Prússia, atual Alemanha. Esta citação encontra-se na obra "Sobre a Pedagogia". 
social resultante da falta de planejamento do império e as quase inexistentes alternativas de ocupação à massa de negros libertos. Índices superiores a $80 \%$ de desempregos entre homens de cor, a chegada de novos concorrentes vindos de longe (Europa) e as dificuldades para exercer a cidadania concedida ajudam a compreender a gravidade da crise.

O letramento emerge, naquele momento, como o único caminho viável ao exercício da cidadania. E os movimentos negros existentes que denunciam o status dos ex-escravos nos jornais, transformam-se nos principais financiadores do acesso à educação. Mesmo em face à miséria coletiva daqueles dias, as lideranças existentes nos impressos negros, como os irmãos Arlindo e Isaltino Veiga dos Santos, fundadores da Frente Negra Brasileira (FNB), articulam a comunidade para arrecadar fundos para a construção e manutenção de escolas. No coração da articulação local, a dupla ajudou a construir e disseminar o movimento que chegou a arregimentar 200 mil afiliados em todo país, além de criar aquele que foi o primeiro e único partido negro brasileiro ${ }^{2}$.

A iniciativa resultou num sucesso tão impressionante que despertou a atenção dos grupos políticos existentes no período, independente da linha ideológica. O potencial da Frente Negra atraiu movimentos de esquerda e de direita que lutaram abertamente pela influência dos frentenegrinos. Nas páginas dos jornais travou-se uma verdadeira guerra marcada pela virulência do discurso, que não poupava farpas e acusações de toda ordem. Arlindo, em especial, por suas convicções monarquistas, religiosas e alinhadas ao Integralismo, de Plínio Salgado ${ }^{3}$, foi

2 Criado no início da década de 30, o grupo diferenciava-se pelo nível educacional. A maioria dos integrantes era alfabetizada e tinha consciência dos desafios encontrados pelos negros depois da Abolição. A FNB era composta de vários departamentos (Educacional, Musical, Esportivo, Médico e Jurídico Social). Seus ideais espalharam-se para outros estados do país: Bahia, Pernambuco, Espírito Santo, Rio Grande do Sul e Minas Gerais. Em outubro de 1934, a instituição foi a primeira a fundar um partido político negro, registrado na Justiça Eleitoral.

3 Líder e fundador da Ação Integralista Brasileira (AIB). Amigo pessoal do fundador da FNB, chegou a publicar artigos em "A Voz da Raça". 
um alvo recorrente de críticas do establishment e dos próprios companheiros de jornada pelos direitos dos negros.

Para a compreensão das relações sociais e econômicas existentes naquele contexto a pesquisa avançou, em um segundo momento, na investigação das ideologias que forneceram suporte ao discurso racista. Desde as raízes do que ficou posteriormente conhecido como Racismo Científico até suas inúmeras ramificações e variações. Entre os primeiros discursos claramente identificado como racistas está o de Johann Friedrich Blumenbach, responsável pela criação da ideia de raças humanas e as investigações de craniologia, "ciência" na qual a avaliação do tamanho da cabeça assume uma função determinante para a compreensão do potencial humano e a identificação de "semelhanças" com os animais.

Mais tarde, uma longa linhagem de teóricos como Robert Knox, Samuel George Morton, J. Arthur de Gobineau, Gustave Le Bom, Hippolyte Taine e Houston Stewart Chamberlain, vai encorpar o grupo de teóricos que transformaram a ciência no principal argumento para justificar o racismo e com ele todas as iniciativas imperialistas e o modelo neocolonial. Um discurso que estabelecia como verdade o fato de que homens identificados como "superiores" tinham o direito, senão o dever, de estabelecer a dominação de povos classificados como "inferiores". É interessante ressaltar que nem sempre o discurso de diferenciação seguiu os modelos eurocêntricos. No Brasil identificam-se algumas particularidades, como a Teoria do Eo mbranquecimento, no qual acreditava-se que a miscigenação haveria de ser o elemento de transformação de "raças inferiores" em branca, a "raça superior".

Ao contrário do observado no hemisfério norte, onde os "cientistas raciais" associavam o Racismo Científico ao Poligenismo (teoria em que a humanidade descende de espécies distintas e, portanto, não passíveis de cruzamento), oficialmente o governo brasileiro defendeu a ideia de "clareamento" da raça pela mistura. De casamento em casamento, a população brasileira iria, enfim, encontrar a "redenção". Desse modo, acreditavam que num período curto, os homens e mulheres negros teriam 
desaparecido. A expectativa do diretor do Museu Nacional, João Baptista de Lacerda, conforme documento apresentado no I Congresso Universal de Raças, em Londres (1911), era de que tal prognóstico seria alcançado à "entrada do novo século (XXI)".

O tema miscigenação ganha relevância anos mais tarde, na década de 1930, durante a Era Vargas, quando o mestiço é alçado a símbolo nacional, passando a representar a imagem de uma nação onde as diferenças entre raças são menosprezadas. A ideia de um país de misturas e sincrético não foi, no entanto, além do discurso oficial. Conforme investigado na dissertação de mestrado desta autora, a educação em quase todo o território permaneceu como uma atividade restrita aos negros que continuavam a recorrer às associações para que, juntas, pudessem organizar atividades diversas para manter o espaço do ensino, professores e o mínimo necessário à infraestrutura e demais funcionários.

A reflexão sobre o impacto - ontem e hoje - da exposição há centenas de anos de discurso científico racista sobre os afrodescendentes se deu com base na obra do pensador africano Achiles Mbembe, na qual destacamos "Crítica da Razão Negra" (2014). No livro, que refaz os passos da construção do pensamento racial europeu e suas máscaras, é analisado o conjunto de discursos e práticas criados, contados e repetidos com o objetivo de colocar o negro enquanto sujeito de raça e exterioridade selvagem, passível de desqualificação moral e de instrumentalização prática.

O coração da pesquisa foi o questionamento "Onde somos África?”. A investigação foi realizada nos textos publicados em "A Voz da Raça", ao longo de cinco anos e trouxe desafios de todo tipo e ordem. O primeiro foi o estabelecimento de critérios que permitissem a identificação das permanências das diversas culturas africanas desterradas na diáspora. A partida foi dada pelo rastreamento de temas relacionados ao continente negro,

4 Nascido nos Camarões em 1957, Ph.D. em História pela Universidade de Sorbonne, em Paris, França, e professor em Duke, na Virgínia, Estados Unidos; e Witwaterand, em Joanesburgo, África do Sul, Achiles Mbembe é conhecido como um dos mais importantes interlocutores atuais sobre história e política africanas. 
com o auxílio da tese de doutoramento em Educação de Rosângela Ferreira de Souza, "Pelas Páginas dos Jornais: Recortes Identitários e Escolarização Social do Negro em São Paulo”, defendida junto à Universidade de São Paulo, em 2013.

Dos 43 temas identificados como recorrentes pela pesquisadora, foi observado que apenas seis se repetiam em pelo menos cinco anos de publicação: Raça Negra (26); Abolição da Escravidão / 13 de maio (16); Instrução / Educação (16); Figuras Históricas (12); Associativismo Negro (10) e Preconceito (5). A África raramente é citada quando o tópico é a própria raça. As referências estão restritas ao continente, identificado como antigo e lendário, "misterioso", impenetrável, restando ao Brasil o papel de paradigma a ser seguido. $\mathrm{O}$ mesmo acontece no tema da Abolição ou mesmo da Instrução.

Aos desterrados, de fato, restaram poucas referências da terra-mãe. Separados de suas famílias na partida, proibidos de manter suas crenças e tradições culturais, aos escravos sobrou a tradição oral, os poucos registros históricos no caso de figuras-chave como Henrique Dias ${ }^{5}$ e Zumbi ${ }^{6}$. O que se testemunha nos séculos seguintes, em especial no início do século $\mathrm{XX}$, foi a resistência silenciosa nas práticas religiosas sincréticas ou na clandestinidade, promovida por leis claramente discriminatórias.

Mesmo nas escolas instituídas por movimentos, como a Frente Negra Brasileira, observa-se o desconhecimento com relação à África e a quase completa falta de informações relativas ao continente. Como observado no trabalho, as expressões populares como o carnaval e a capoeira terminaram por ser as tradições nacionais mais vinculadas às origens. Nos movimentos e cantos identificamos o gingado, as danças, valores e lideranças ancestrais. Graças a agremiações paulistas, como a Camisa Verde e a Vai-Vai, a despeito de críticas e perseguições da época, os laços com o continente permaneceram.

\footnotetext{
5 Filho de escravos que se tornou herói nacional no combate às invasões holandesas (? - 1662).

6 Zumbi (1655-1695), escravo fugido que liderou o quilombo de Palmares.
} 
Nas páginas de "A Voz da Raça” estão documentadas a organização desses grupos e a preparação para o desfile das escolas de samba, como a escolha do tema, composições e ensaios. A entrega anual de um troféu aos melhores desempenhos no Carnaval ${ }^{7}$ revela a importância do tema para a comunidade, ainda que fosse alvo de críticas internas. Para alguns integrantes da FNB de viés mais tradicionalista, a "festa da carne" era ocasião de perdição para a juventude negra que se entregava ao álcool e ao sensualismo. Sobravam críticas também para a alienação dos foliões e a atenção dedicada ao evento, reconhecido apenas como "recreativo".

Ainda que de maneira inconsciente, um dos mais interessantes modelos observados de permanência da herança africana é a língua. $\mathrm{O}$ exame da língua portuguesa, especialmente a falada em território brasileiro, comprova a existência de inúmeras palavras de origem africana. Neste trabalho optou-se pela investigação do tronco Banto, utilizado por um grande número de línguas e dialetos negroafricanos. Elas são especialmente importantes para os brasileiros devido à predominância pelas línguas Quicongo, Umbundo e o Quimbundo.

Essa dissertação particularmente guarda com especial valor o fato de os negros bantos terem sido destinados aos estados do Maranhão, Pará, Pernambuco, Alagoas, Rio de Janeiro e São Paulo. Para investigar e rastrear, nas páginas de "A Voz da Raça", os ecos deste idioma foram realizados dois movimentos-chave: em primeiro lugar, a leitura e o "garimpo" no "Dicionário Banto do Brasil", de Nei Lopes (1999), a procura de palavras incorporadas ao dia a dia dos brasileiros, como, por exemplo, cutucar, cochichar, empacar, paparicar, xingar e zombar. Em seguida procedeu-se a procura nos artigos, editoriais e reportagens da utilização, ainda que sem a consciência desse fato, desses mesmos termos e expressões africanas.

\footnotetext{
A taça Artur Friedenreiche era oferecida aos Cordões Carnavalescos da Gente Negra Paulista pela Frente Negra Brasileira com o objetivo de reconhecer o talento e o trabalho dos foliões.
} 
Essa África silenciosa, mas profundamente presente, emociona. Dos mais de seis mil verbetes listados no Dicionário Banto, de Nei Lopes, 133 palavras foram identificadas com presença marcante em nosso português de hoje. Com a ajuda da ferramenta de busca no site da Biblioteca Nacional, a Hemeroteca Digital, , não foi difícil encontrar 25 vocábulos largamente utilizados pelos frentenegrinos, ainda - como já ressaltado - de maneira inconsciente, desprovida de qualquer relação intencional com o continente africano, sua cultura ou herança em território brasileiro.

O advogado, compositor e filólogo Nei Lopes explica na abertura de seu dicionário que das três marcas que facilitam a identificação dos vocábulos bantos destacam-se a presença das sílabas iniciais BA, CA, CU, FU, MA, MO, MU, QUI (caçula, candango, macumba, maxixe, moleque, quitanda etc.); a identificação no interior dos vocábulos dos grupos consonantais $\mathrm{MB}, \mathrm{ND}, \mathrm{NG}$ (samba, bunda, camundongo, ginga, tanga, sunga, catinga etc.) e as terminações AÇA, ILA, ITA, IXE, UTE, UCA (quizila, catita, muvuca etc.). Uma breve análise destas palavras surpreende pela presença e uso do domínio público.(Em "Dicionário Banto do Brasil", p. 21).

Só na palavra "cozinha" encontramos uma presença marcante que vai dos utensílios, como a caçamba (kisambu, cesta, cesto grande), aos ingredientes, como o jiló (luó, muito amargo), cachaça (kachasu, aguardente), marafo (malavu, vinho) e garapa (ngalapa, bebida formada pela mistura de mel e açúcar com água); aos pratos, como a farofa (falofa, mistura de farinha, azeite ou água), angu (bungu, pirão ou papa de farinha de milho, arroz, mandioca ou banana cozida) e quibebe (quibebe, papa de abóbora preparada de várias formas e acompanhamentos diversos). Isso sem contar as expressões correlatas, e muito presentes, como angu-de-caroço, anguada, confusão.

A música e a dança são guardiãs de inúmeros vocábulos afro, de origem banto, encontrados em nosso dia a dia. Expressões da percussão, como batuque (bu-atuka, onde se salta ou se pinoteia); a instrumentos como a cuíca (khwita, tambor de fricção que deu origem ao instrumento brasileiro) e ritmos, como o samba (disemba, umbigada), o cateretê (de catete, pássaro 
africano), dança rural cantada, executada em fileiras opostas, e a milonga (milonga, queixa, calúnia, injúria), música e dança de origem platina.

O cruzamento da pesquisa de Nei Lopes com os textos publicados no jornal da Frente Negra Brasileira (FNB) demonstra que a presença africana perpassa todo o discurso do brasileiro. Está em toda parte, das expressões que definem as emoções diárias às partes do corpo - uma cultura exportada pela diáspora africana e que se reinventou no dia a dia em registros do homem comum. Na bagunça (bangunza, desordem, confusão) dos moleques (muleke, garoto, filho) bambas (dbamba, valentão) até a birita (jeribita, cachaça) para engabelar (de engambelo, uyambelo, presente que se dá ao curandeiro, engodo, embuste) o banzo (mbonzo, saudade).

A partir desse mergulho provocado pela análise dos textos do jornal "A Voz da Raça", foram elencadas algumas considerações finais. Entre elas destacamos a veemente denúncia elaborada pelos frentenegrinos e que propicia, hoje, a sociólogos, historiadores, antropólogos e profissionais de outras áreas como a Educação e a Imprensa, um retrato das condições enfrentadas pelos negros recém-libertos (desemprego, abandono e exclusão) e o quanto desse problema ainda se perpetua na sociedade brasileira.

Essa declaração negra nas páginas de A Voz, ainda que muitas vezes expressos em um discurso hegemônico, branco ora pelo desejo de aceitação em uma sociedade excludente, ora pelo direcionamento de seu criador e diretor (Arlindo Veiga dos Santos) - tem profundas raízes africanas que permanecem submersas. Elas podem ser observadas em especial na língua portuguesa, repleta de palavras africanas, desconhecidas em sua maioria dos brasileiros daquela época e ainda nos dias de hoje.

A busca pelo aprofundamento desse momento histórico alinha-se com o determinado pela Lei 10.639/03. A identificação de um protagonismo negro que inspire e desafie novos jovens a investigar, aprofundar e iluminar os alunos. A dissertação aqui analisada termina com uma provocação no sentido de instigar novos mergulhos à procura das raízes africanas, seja do ponto de vista de abertura de caminhos inéditos e entendimentos da formação 
e do pensar do brasileiro, seja na ampliação em nossa pátria de pontos de intercessão com outros países do continente africano e que falam o português, como Angola, Cabo Verde, Guiné-Bissau, Guiné Equatorial, Moçambique e São Tomé e Príncipe.

\section{REFERÊNCIAS}

BARBOSA, Márcio. Frente Negra Brasileira - Depoimentos. São Paulo, SP: Quilombo hoje, (2007).

BASTIDE, Roger. FERNANDES, Florestan. Brancos e negros em São Paulo. 2a edição. São Paulo, SP: Companhia Editora Nacional, (1959).

BASTIDE, Roger. A Imprensa Negra do Estado de São Paulo. Universidade de São Paulo. Faculdade de Filosofia, Ciências e Letras. Boletim CXXI. Sociologia n.2. Estudos Afro-brasileiros, 2a. Série, (1951).

CUTI, Luiz Silva. E disse o velho militante José Correia Leite. São Paulo, SP: Prefeitura do Município de São Paulo / Secretaria Especial de Cultura / Coordenadoria Especial do Negro, (1992).

DOMINGUES, Petrônio. O Recinto sagrado: Educação e antirracismo no Brasil. Cadernos de Pesquisa, v.39, n.138, p.963-994, set./dez. 2009.

FERNANDES, Florestan. O negro no mundo dos brancos. São Paulo: Difel, 1972.

GOMES, Flávio; DOMINGUES, Petrônio (Org). Políticas da raça - Experiências e legados da abolição e da pós-emancipação no Brasil. Edições Selo - Negro São Paulo/SP - 2014. Artigo 10 - Negro político, sociedade branca: Alfredo Casimiro da Rocha como exceção e estudo de caso (São Paulo, décadas de 1880 a 1930), por James Woodard.

GUimarãES, Antônio Sérgio Alfredo. Preconceito Racial: modos, temas e tempos. 2a ed. São Paulo: Cortez, 2012.

.Raça e os estudos de relações raciais no Brasil. Novos Estudos Cebrap, São Paulo: n.54, p.147-156, jul. 1999.

HOFBAUER, Andreas. Branqueamento e democracia racial: Sobre as entranhas do racismo no Brasil. Marília (SP): Unesp, 2006.

LOPES, Nei. Novo dicionário banto do Brasil. Rio de Janeiro: Pallas, 1999. Dicionário Escolar Afro-brasileiro. São Paulo, Selo Negro, 2006.

Selo Negro, 2004.

Enciclopédia Brasileira da Diáspora Africana. São Paulo,

MBEMBE, Achille. Crítica da razão negra. $2^{a}$ edição. Lisboa: Editora Antígona, 2017.

MALATIAN, Teresa. O Cavaleiro Negro. São Paulo, SP: Unesp, 2017.

KANT, Immanuel. Sobre a Pedagogia. Piracicapa, SP: Editora Unimep (Universidade Metodista de Piracicaba), 2006. 
CARVAlHO, Gilmar. A Imprensa Negra Paulista entre 1915 e 1937: características, mudanças e permanências.. Dissertação de Mestrado em História Econômica - Universidade de São Paulo (USP), São Paulo, 2009

DOMINGUES, Petrônio José. Uma História não contada. Negro, racismo e trabalho no Pós-Abolição em São Paulo (1889-1930). Dissertação de Mestrado em História - Universidade de São Paulo (USP), São Paulo, 2001

A insurgência do Ébano: A História da Frente Negra Brasileira (1931-1937). Tese de Doutorado em História - Universidade de São Paulo (USP), São Paulo, 2005

OLIVEIRA, Laiana Lannes de. A Frente Negra Brasileira: Política e questão racial nos anos 1930.. Dissertação de mestrado em História - Universidade do Estado do Rio de Janeiro (Uerj), Rio de Janeiro, 2002

Entre a Miscigenação e a Multirracialização: Brasileiros Negros ou Negros Brasileiros? Os Desafios do Movimento Negro Brasileiro no Período de Valorização Nacionalista (1930-1950) - A Frente Negra Brasileira e o Teatro Experimental do Negro. Tese de Doutorado em História - Universidade Federal Fluminense (UFF), Rio de Janeiro, 2008

PINTO, Regina Pahim. O Movimento Negro em São Paulo: Luta e Identidade.. Tese de doutorado em Antropologia - Universidade do Estado de São Paulo (USP) - São Paulo, SP, 1993

SOUZA, Rosângela Ferreira de. Pelas Páginas dos Jornais: Recortes Identitários e Escolarização do Negro em São Paulo (1920-1940). Tese de Doutoramento em Educação - Universidade de São Paulo (USP), São Paulo, 2013

Hemeroteca da Biblioteca Nacional -

bndigital.bn.gov.br/hemeroteca-digital/

Os exemplares de "A Voz da Raça" acesso em setembro de 2018.

\section{Sobre a autora}

Formada em Comunicação Social, com habilitação em Jornalismo pela Faculdade Federal Fluminense (UFF); pós-graduada em Teoria da Arte, pela Universidade Estadual do Rio de Janeiro (Uerj), Ariadne Guimarães Dias possui ainda MBA em Finanças Corporativas pelo IBMEC e em Finanças Corporativas pela FIA/USP. Trabalhou em jornais, revistas, rádios e TVs brasileiros e publicou dois livros - "Mata Atlântica, Coração Verde do Brasil", Ed. Paper Mill, e "O Livro dos Santos”, pela Editora Ediouro 